\title{
Study on Hydrolysis of Magnesium Hydride by Interface Control
}

\author{
Yanyan Chen $(\mathbb{D}$, Ming Wang, Fenggang Guan, Rujun Yu, Yuying Zhang, Hongyun Qin, \\ Xia Chen, Qiang Fu $\mathbb{D}$, and Zeyao Wang
}

\author{
School of Chemistry and Chemical Engineering, Shandong University of Technology, Zibo 255049, China \\ Correspondence should be addressed to Qiang Fu; fuqiang@tju.edu.cn
}

Received 13 August 2020; Revised 11 November 2020; Accepted 24 November 2020; Published 17 December 2020

Academic Editor: K. R. Justin Thomas

Copyright () 2020 Yanyan Chen et al. This is an open access article distributed under the Creative Commons Attribution License, which permits unrestricted use, distribution, and reproduction in any medium, provided the original work is properly cited.

\begin{abstract}
Magnesium hydride $\left(\mathrm{MgH}_{2}\right)$ is one of the competitive hydrogen storage materials on account of abundant reserves and high hydrogen content. The hydrolysis of $\mathrm{MgH}_{2}$ is an ideal and controllable chemical hydrogen generation process. However, the hydrolyzed product of $\mathrm{MgH}_{2}$ is a passivation layer on the surface of the magnesium hydride, which will make the reaction continuity worse and reduce the rate of hydrogen release. In this work, hydrogen generation is controllably achieved by regulating the change of the surface tension value in the hydrolysis, a variety of surfactants were systematically investigated for the effect of the hydrolysis of $\mathrm{MgH}_{2}$ In the meantime, the passivation layer of $\mathrm{MgH}_{2}$ was observed by scanning electron microscope (SEM), and the surface tension value of the solution with different surfactants were monitored, investing the mechanism of hydrolysis adding different surfactants. Results show that different surfactants have different effects on hydrogen generation. The hydrogen generation capacity from high to low is as follows: tetrapropylammonium bromide (TPABr), sodium dodecyl benzene sulfonate (SDBS), Ecosol 507, octadecyl trimethyl ammonium chloride (OTAC), sodium alcohol ether sulfate (AES), and fatty methyl ester sulfonate (FMES-70). When the ratio of $\mathrm{MgH}_{2}$ to $\mathrm{TPABr}$ was $5: 1$, the hydrogen generation was increased by $52 \%$ and $28.3 \%$, respectively, at the time of $100 \mathrm{~s}$ and $300 \mathrm{~s}$. When hydrolysis time exceeds $80 \mathrm{~s}$, the hydrogen generation with AES and FMES-70 began to decrease; it was reduced by more than $20 \%$ at the time of $300 \mathrm{~s}$. SEM reveals that surfactants can affect the crystalline arrangement of $\mathrm{Mg}(\mathrm{OH})_{2}$ and make the passivation layer three-dimensionally layered providing channels for $\mathrm{H}_{2} \mathrm{O}$ molecules to react with $\mathrm{MgH}_{2}$.
\end{abstract}

\section{Introduction}

With the rapid development of industrial technology, the global demand for energy is growing exponentially. Fossil fuels, as the most widely used energy materials, are not renewable, environmental pollution, and other defects; therefore, it is an urgent problem to find new clean and efficient energy sources at the present stage. Hydrogen has the characteristics of environmental protection, renewable, and high heat energy. Since the 1970s, it has been widely concerned by researchers. Hydrogen storage and release technology limits the development and application of hydrogen energy [1-4]. Among many hydrogen storage materials, the hydrogen content of $\mathrm{MgH}_{2}$ reaches 7.69\% (wt. \%), and its theoretical hydrolysis hydrogen yield is $15.3 \%$ (wt. \%) [5, 6]. Magnesium hydride is considered one of the best choices for portable hydrogen fuel cells due to stable storage and mild hydrolysis [7-19]. The chemical equation of the reaction between $\mathrm{MgH}_{2}$ and $\mathrm{H}_{2} \mathrm{O}$ is as following:

$$
\mathrm{MgH}_{2}+2 \mathrm{H}_{2} \mathrm{O} \longrightarrow \mathrm{Mg}(\mathrm{OH})_{2} \downarrow+2 \mathrm{H}_{2} \uparrow \cdots \Delta H=-277 \mathrm{KJ} \mathrm{mol}^{-1}
$$

The magnesium hydroxide is difficult to dissolve in water whose solubility product is $5.6 \times 10^{-12} \mathrm{~mol}^{3} \cdot \mathrm{L}^{-3}$. It easily forms the passivation layer during the hydrolysis process, prevents the diffusion of water molecules toward the surface of magnesium hydride, reduces the rate, and shortens the duration of hydrolysis reaction [20-22]. Eliminating the cladding effect of magnesium hydroxide passivation layer on $\mathrm{MgH}_{2}$ has become an urgent problem to be solved in the hydrogen yield of hydrolysis [23]. 


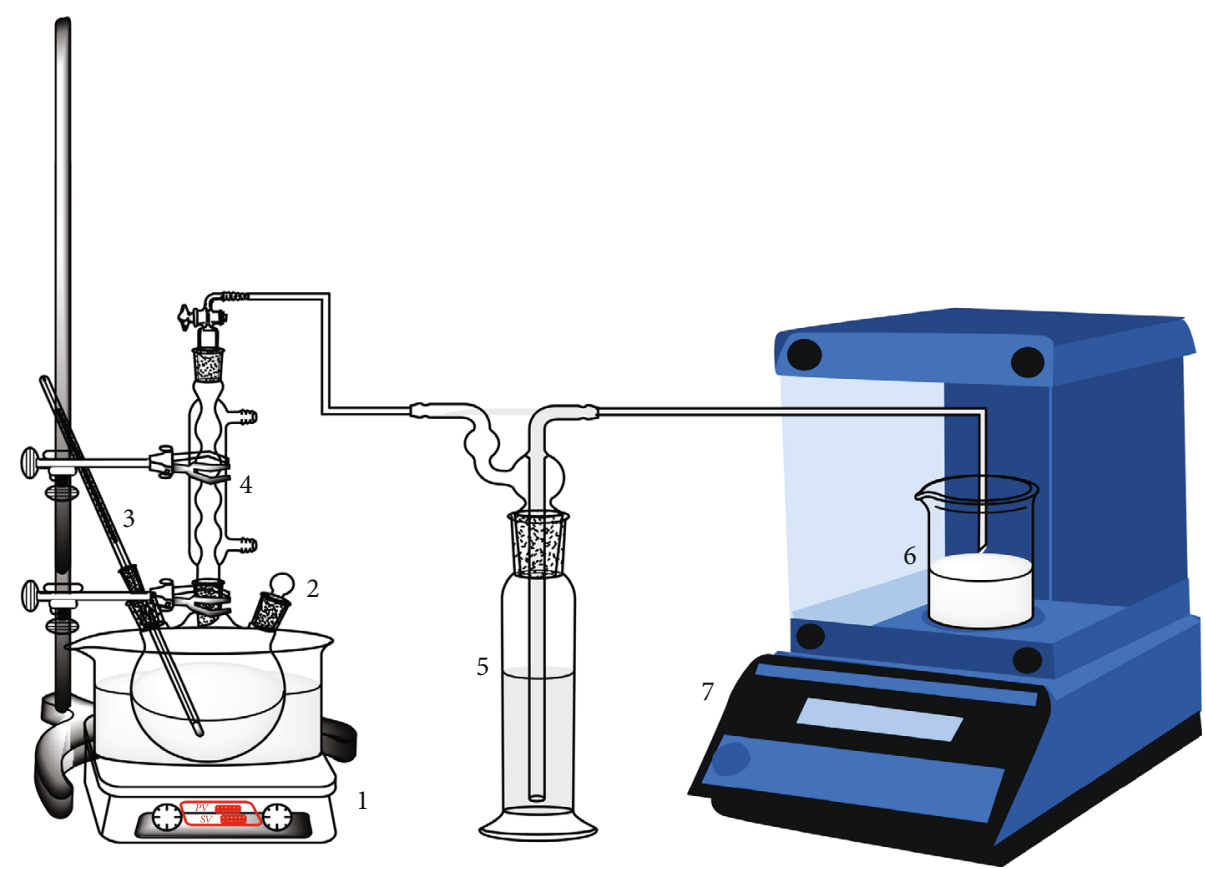

FIGURE 1: Hydrolysis unit. ((1) water bath, (2) three-necked flask, (3) thermometer, (4) condenser, (5) gas washing bottle, (6) beaker, and (7) analytical balance).

As we all know, surfactants can change the surface tension of the solution by means of forming an adsorbed layer with a certain orientation at the solid-liquid interface [24-27]. Based on the above principles, this study selected several typical surfactants to study the influence on the quantity of hydrogen generation and the rate of hydrogen generation. These data were combined with the surface tension value of the aqueous solution and the scanning electron micrograph of the product to analyze the corresponding mechanism. The study of interface control in this work provides the theoretical basis for the future researches of $\mathrm{H}_{2}$ generation by hydrolysis of $\mathrm{MgH}_{2}$.

\section{Experimental}

2.1. Experimental Materials. $\mathrm{H}_{2}$ is generated from the reaction of $\mathrm{MgH}_{2}$ (purity $\geq 99.5 \%$, MG Power Technology Co., Ltd) and $\mathrm{H}_{2} \mathrm{O}$ (deionized water). To investigate the effects of surfactants on the generation of $\mathrm{H}_{2}$, different series of surfactants were added into deionized water: sodium dodecyl benzene sulfonate (SDBS, purity $\geq 90.0 \%$, Shandong Yousuo Chemical Technology Co., Ltd), fatty methyl ester sulfonate (FMES-70, purity $\geq 70.0 \%$, Shandong Yousuo Chemical Technology Co., Ltd), sodium alcohol ether sulfate (AES, purity $\geq 70 \%$, Shandong Yousuo Chemical Technology Co., Ltd), tetrapropylammonium bromide (TPABr, purity $\geq 99.0 \%$, Sinopharm Chemical Reagent Co., Ltd), octadecyl trimethyl ammonium chloride (OTAC, purity $\geq 99.5 \%$, Shandong Yousuo Chemical Technology Co., Ltd), and Ecosol 507 (purity $\geq 90.0 \%$, Shandong Yousuo Chemical Technology Co., Ltd).

2.2. Experimental Device and Process. The experimental device (Figure 1) is composed of the reaction system and the metering system. The reaction system is composed of a $250 \mathrm{~mL}$ three-necked flask, a condenser, a thermometer, and a water bath; the metering system is composed of a gas washing bottle, a beaker, and an analytical balance. The two systems are connected with silicone tubes.

Firstly, add $200 \mathrm{~mL}$ of water to a $250 \mathrm{~mL}$ three-necked flask. After the temperature of the water bath reaches $70^{\circ} \mathrm{C}$, surfactant and stir were added. Then, the magnesium hydride was put to the three-necked flask. The hydrogen produced by hydrolysis is condensed by the condenser. An equal volume of water of gas washing bottle was discharge. Finally, the volume of hydrogen generated was calculated as follows:

$$
V_{\mathrm{H}_{2}}=\frac{m_{\mathrm{H}_{2} \mathrm{O}}}{\rho_{\mathrm{H}_{2} \mathrm{O}}}
$$

2.3. Analytical Method. The surface morphology and dispersion state of magnesium hydride and hydrolyzed products are tested by SEM (Quanta 250, FEI); the surface tension (ST) of aqueous solutions with different surfactants is tested by surface tension meter K100C-MK2.

\section{Results and Discussion}

Surfactants with different groups, structures, and dosages have different impacts on the surface energy and the wetting effect between solid and liquid.

3.1. Effect of Anionic Surfactant. According to the structure of hydrophilic groups, anionic surfactants mainly include sulfonate and sulfate ester salts. Typical anionic surfactants were used in this study: SDBS, AES, and FMES-70. 


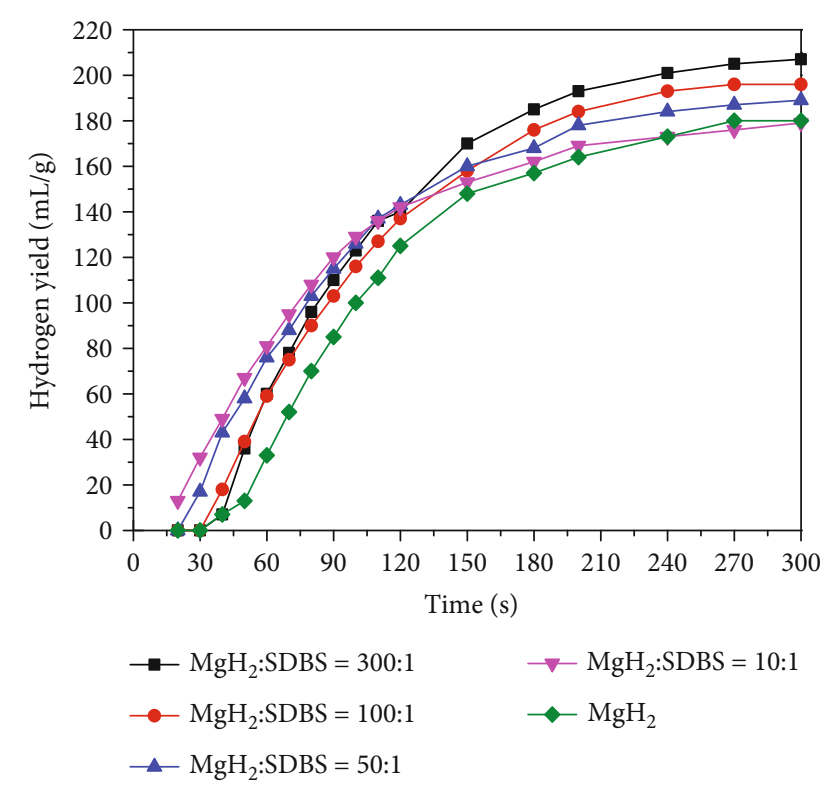

FIGURE 2: The effect of different SDBS dosages on hydrogen generation.

TABLE 1: Surface tension values of aqueous solutions with different SDBS dosages.

\begin{tabular}{lc}
\hline Ratio* & ST $(\mathrm{mN} / \mathrm{m})$ \\
\hline Water & 71.57 \\
$\mathrm{MgH}_{2}: \mathrm{SDBS}=300: 1$ & 70.51 \\
$\mathrm{MgH}_{2}: \mathrm{SDBS}=100: 1$ & 59.00 \\
$\mathrm{MgH}_{2}: \mathrm{SDBS}=50: 1$ & 47.80 \\
$\mathrm{MgH}_{2}: \mathrm{SDBS}=10: 1$ & 38.48 \\
\hline
\end{tabular}

*: the ratio represents dosages of surfactants in experiments without $\mathrm{MgH}_{2}$.

Under the same condition, the volume of the water, the temperature of the water bath, and the mass of $\mathrm{MgH}_{2}$, surfactants with different dosages were added, time (seconds) is the $x$-coordinate, and hydrogen yield $(\mathrm{mL} / \mathrm{g})$ is the $y$-coordinate.

It is shown in Figure 2 that the hydrogen generation rate are approximately the same at $110 \mathrm{~s}$ when $\mathrm{MgH}_{2}: \mathrm{SDBS}=300: 1, \quad \mathrm{MgH}_{2}: \mathrm{SDBS}=50: 1$, and $\mathrm{MgH}_{2}:$ $\mathrm{SDBS}=10: 1$. While the hydrogen generation rate is slightly lower when $\mathrm{MgH}_{2}: \mathrm{SDBS}=100: 1$ at $110 \mathrm{~s}$. When the hydrolysis time is $120 \mathrm{~s}$, the hydrogen generation rate of $\mathrm{MgH}_{2}: \mathrm{SDBS}=300: 1$ is greater than the other. When the hydrolysis time is $155 \mathrm{~s}$, the hydrogen generation rate of $\mathrm{MgH}_{2}: \mathrm{SDBS}=100: 1$ is higher than $\mathrm{MgH}_{2}: \mathrm{SDBS}=10: 1$ and $\mathrm{MgH}_{2}: \mathrm{SDBS}=50: 1$. All the hydrogen generation rate reduces gradually over $200 \mathrm{~s}$. The final hydrogen yield are ranked as follows: $\mathrm{MgH}_{2}: \mathrm{SDBS}=300: 1>\mathrm{MgH}_{2}: \mathrm{SDBS}=100: 1>$ $\mathrm{MgH}_{2}: \mathrm{SDBS}=50: 1>\mathrm{MgH}_{2}: \mathrm{SDBS}=10: 1=\mathrm{MgH}_{2}$.

The hydrogen generation rate will improve with the increase of SDBS dosages (time $\leq 100 \mathrm{~s}$ ). It is possible that the surface tension of water becomes lower as surfactants increase (it is presented in Table 1). However, the lower the surface tension, the easier bubbles will foam. These bubbles

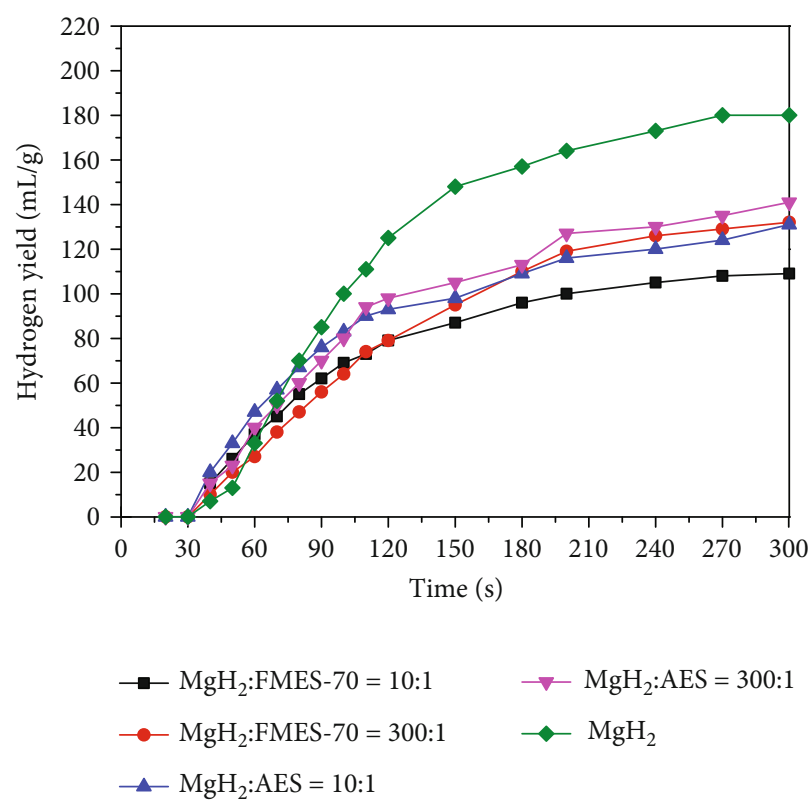

FIgURE 3: The effect of different FMES-70, AES dosages on hydrogen generation.

TABLE 2: Surface tension values of aqueous solutions with different FMES-70, AES dosages.

\begin{tabular}{lc}
\hline Ratio & ST $(\mathrm{mN} / \mathrm{m})$ \\
\hline Water & 71.57 \\
$\mathrm{MgH}_{2}:$ FMES-70 = 300:1 & 45.25 \\
$\mathrm{MgH}_{2}:$ FMES-70 = $10: 1$ & 39.74 \\
$\mathrm{MgH}_{2}:$ AES $=300: 1$ & 30.05 \\
$\mathrm{MgH}_{2}:$ AES $=10: 1$ & 37.86 \\
\hline
\end{tabular}

gather into a foam layer, which binds $\mathrm{H}_{2}$. It is difficult for $\mathrm{H}_{2}$ escape from the reaction system (e.g., the curve of $\mathrm{MgH}_{2}: \mathrm{SDBS}=10: 1$ in the Figure 2). Besides, the SDBS concentration is bigger than the critical micelle concentration $\left(\mathrm{CMC}=1.47 \times 10^{-3}-1.60 \times 10^{-3} \mathrm{~mol} / \mathrm{L}\right)$ when $\mathrm{MgH}_{2}: \mathrm{SDBS}=$ $10: 1$. Self-polymerization process of SDBS molecules possibly employed, which inhibits the detachment of $\mathrm{Mg}(\mathrm{OH})_{2}$ from the surface of $\mathrm{MgH}_{2}$ and the dispersion of $\mathrm{Mg}(\mathrm{OH})_{2}$ in the water.

From Figure 3, the hydrogen generation of two experiments $\left(\mathrm{MgH}_{2}: \mathrm{FMES}=10: 1, \mathrm{MgH}_{2}: \mathrm{AES}=10: 1\right)$ are $100 \%$ and $153.8 \%$ at the hydrolysis time of $50 \mathrm{~s}$, which is higher than that without surfactant. When the hydrolysis time is over $75 \mathrm{~s}$, the generation rate of four experiments $\left(\mathrm{MgH}_{2}\right.$ :FMES$70=300: 1, \mathrm{MgH}_{2}:$ FMES-70 = 10:1, $\mathrm{MgH}_{2}: \mathrm{AES}=300: 1$, and $\left.\mathrm{MgH}_{2}: \mathrm{AES}=10: 1\right)$ are lower than that without surfactants.

It is observed from Table 2 that surface tension of solutions becomes lower as the ratio of $\mathrm{MgH}_{2}$ to surfactants increases. On one hand, the system foams more easily $[28,29]$, and the foam layer weakens the diffusion of $\mathrm{H}_{2}$. On the other hand, the hydrolysis reaction is essentially a 


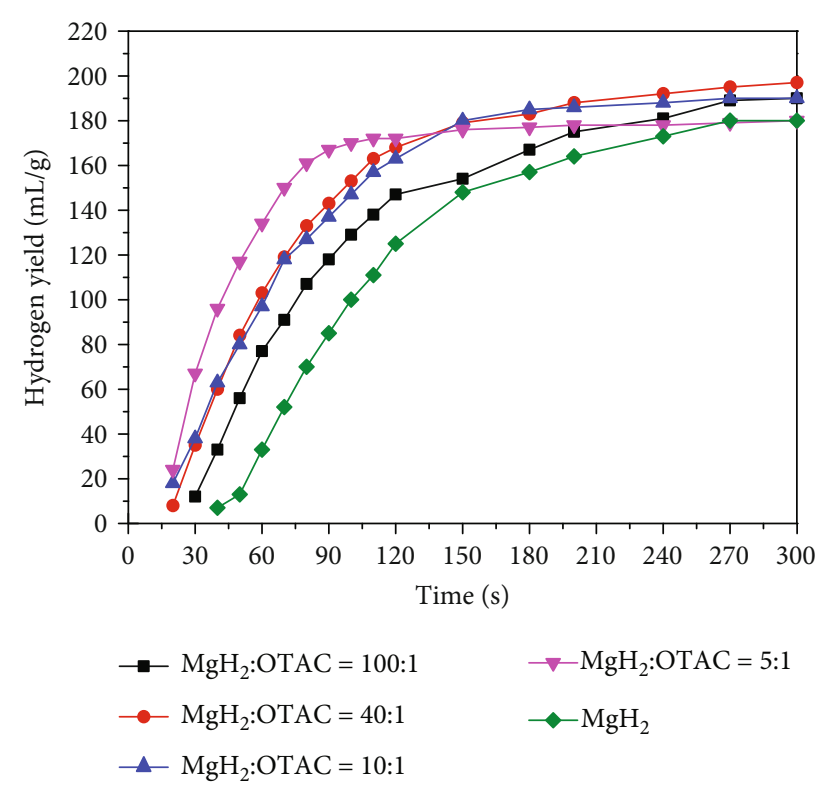

Figure 4: The effect of different OTAC dosages on hydrogen generation.

TABLE 3: Surface tension values of aqueous solutions with different OTAC dosages.

\begin{tabular}{lc}
\hline Ratio & ST $(\mathrm{mN} / \mathrm{m})$ \\
\hline Water & 71.57 \\
$\mathrm{MgH}_{2}:$ OTAC $=100: 1$ & 36.87 \\
$\mathrm{MgH}_{2}:$ OTAC $=40: 1$ & 35.79 \\
$\mathrm{MgH}_{2}:$ OTAC $=10: 1$ & 34.24 \\
$\mathrm{MgH}_{2}:$ OTAC $=5: 1$ & 32.99 \\
\hline
\end{tabular}

reaction with $\mathrm{H}^{+}$, while the negatively charged groups of FMES-70 and AES may combine with $\mathrm{H}^{+}$decreasing the hydrogen generation.

3.2. Effect of Cationic Surfactant. Cationic surfactants are mainly nitrogen-containing organic amine derivatives, composed of a long-chain hydrophobic group and a positive charged hydrophilic group. With good emulsification, wetting effect, and other properties, it is easier to absorb on the solid surface and improves the solid-liquid interface effect.

It is shown in Figure 4 that the hydrogen generation of $\mathrm{MgH}_{2}: \mathrm{OTAC}=5: 1$ and $\mathrm{MgH}_{2}: \mathrm{OTAC}=100: 1$ are $70 \%$ and $29 \%$ higher than that without surfactants at time of $100 \mathrm{~s}$. When the hydrolysis time is over $100 \mathrm{~s}$, the hydrogen generation curves gradually become smooth. At the time of $300 \mathrm{~s}$, the hydrogen generation of $\mathrm{MgH}_{2}: \mathrm{OTAC}=40: 1$ reaches the maximum which is $11.0 \%$ higher than that without surfactants.

Within $120 \mathrm{~s}$ of the hydrolysis, the hydrogen generation and the hydrogen generation rate improve as the ratio of $\mathrm{MgH}_{2}$ to OTAC. After $120 \mathrm{~s}$, the foam layer hinders the continuation of the hydrolysis. It can be seen from Table 3 that the surface tension of $\mathrm{MgH}_{2}: \mathrm{OTAC}=100: 1$ decrease to $36.87 \mathrm{mN} / \mathrm{m}$. When $\mathrm{MgH}_{2}:$ OTAC $=5: 1$, the surface tension

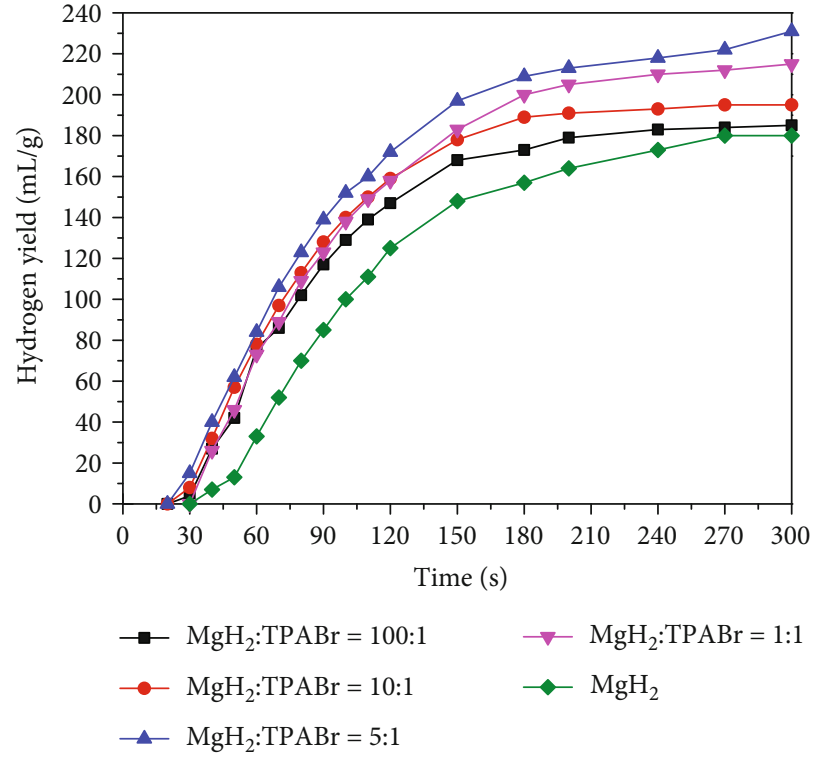

Figure 5: The effect of different TPABr dosages on hydrogen generation.

TABLE 4: Surface tension values of aqueous solutions with different TPABr dosages.

\begin{tabular}{lc}
\hline Ratio & ST $(\mathrm{mN} / \mathrm{m})$ \\
\hline Water & 71.57 \\
$\mathrm{MgH}_{2}: \mathrm{TPABr}=100: 1$ & 61.54 \\
$\mathrm{MgH}_{2}: \mathrm{TPABr}=10: 1$ & 65.39 \\
$\mathrm{MgH}_{2}: \mathrm{TPABr}=5: 1$ & 68.67 \\
$\mathrm{MgH}_{2}: \mathrm{TPABr}=1: 1$ & 69.23 \\
\hline
\end{tabular}

decreases to $32.99 \mathrm{mN} / \mathrm{m}$ slightly. Therefore, OTAC reduces the surface energy of solution preventing the agglomeration of $\mathrm{Mg}(\mathrm{OH})_{2}$ between crystals.

It is also possible that the positively charged groups of the cationic surfactants may combine with $\mathrm{OH}^{-}$inhibiting the combination of $\mathrm{OH}^{-}$and $\mathrm{Mg}^{2+}$ and delay the formation of the passivation layer in the surface of $\mathrm{MgH}_{2}$. Zheng et al. [30] studied the hydrolysis of $\mathrm{Mg}$ in different solutions $\left(\mathrm{MgCl}_{2}, \mathrm{MnCl}_{2}, \mathrm{NiCl}_{2}, \mathrm{AlCl}_{3}, \mathrm{NH}_{4} \mathrm{Cl}\right.$, and $\left.\mathrm{HCl}\right)$. They found that there was a significant improvement in $\mathrm{NH}_{4} \mathrm{Cl}$ and $\mathrm{HCl}$ solution, the conversion efficiency increased by more than $60 \%$. Researchers believe that the higher the affinity between the cations and $\mathrm{OH}^{-}$in the solution, the more effective it is to inhibit the formation of the passivation layer.

In addition, the groups of the cationic surfactants can absorb on $\mathrm{Mg}(\mathrm{OH})_{2}$ along the direction of growth and prevent its growth [31].

Figure 5 reveals the effect of TPABr on hydrogen generation. When the time is $100 \mathrm{~s}$, the hydrogen generation of $\mathrm{MgH}_{2}: \mathrm{TPABr}=5: 1$ and $\mathrm{MgH}_{2}: \mathrm{TPABr}=100: 1$ increases by $52 \%$ and $29 \%$ compared with that without surfactants, respectively. At the time of $300 \mathrm{~s}$, the hydrogen generation of $\mathrm{MgH}_{2}: \mathrm{TPABr}=5: 1$ and $\mathrm{MgH}_{2}: \mathrm{TPABr}=100: 1$ increases by $28.3 \%$ and $3 \%$. 


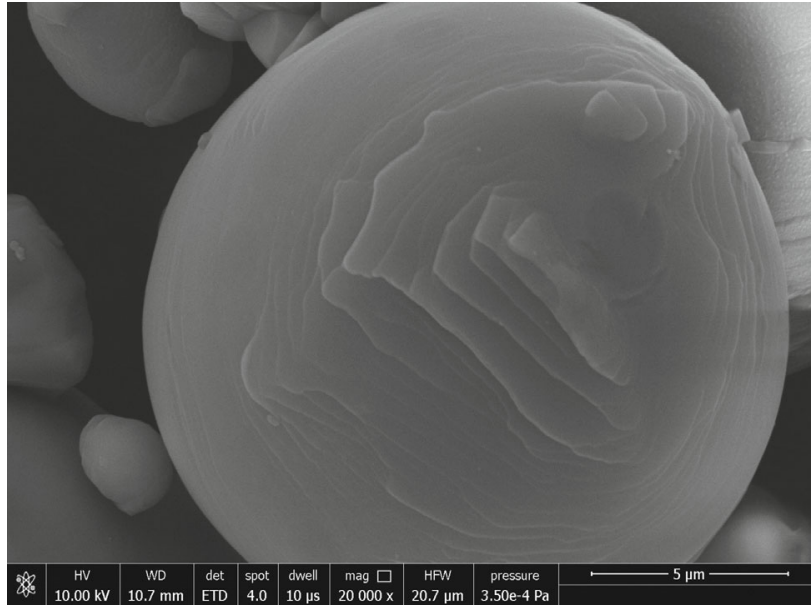

(a)

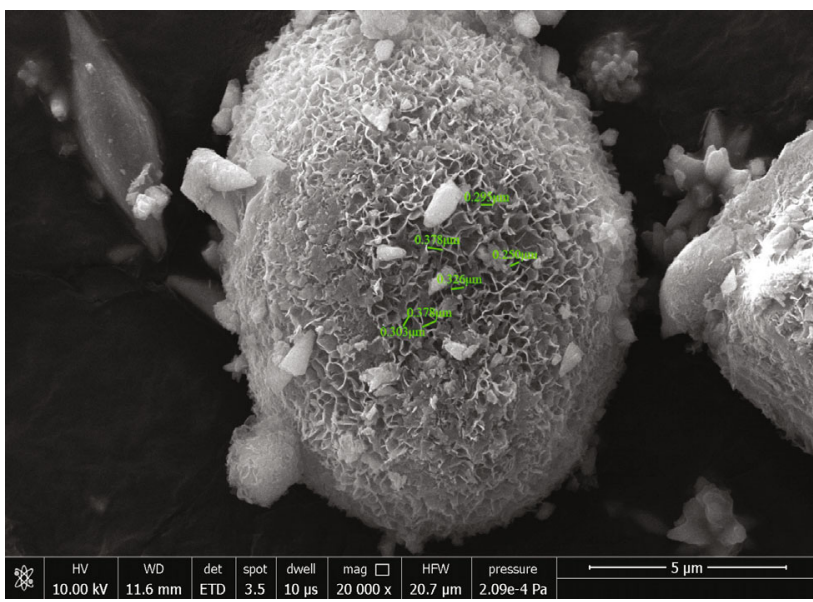

(c)

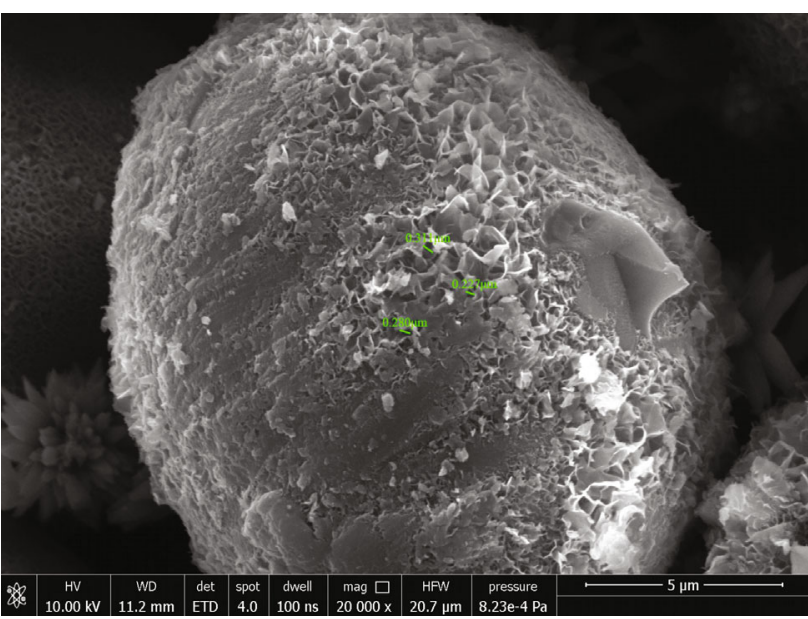

(b)

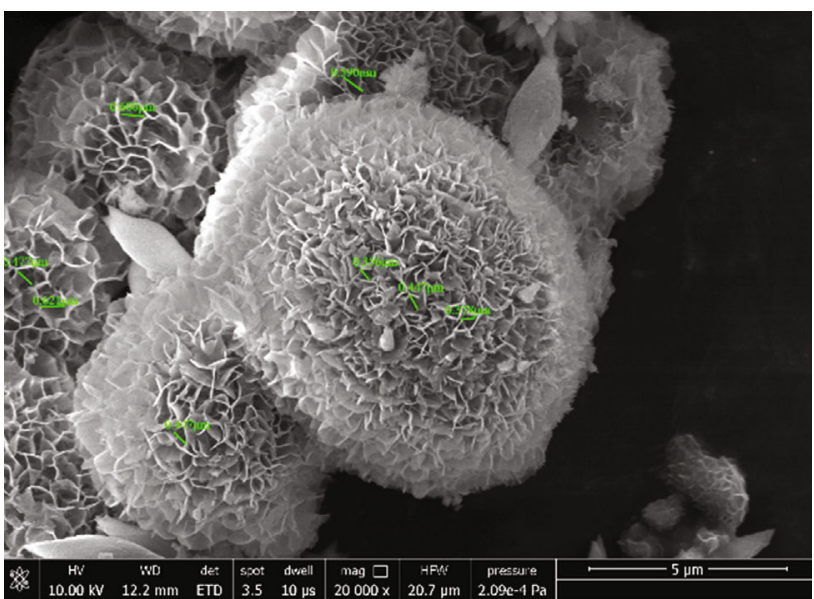

(d)

Figure 6: (a) Magnesium hydride. (b) Hydrolyzed product without surfactants. (c) $\mathrm{MgH}_{2}: \mathrm{SDBS}=300: 1$, hydrolyzed product. (d) $\mathrm{MgH}_{2}: \mathrm{TPABr}=1: 1$, hydrolyzed product $(\times 20000)$.

According to the previous results in this work, the surface tension of solution decreases with the increase of the ratio of $\mathrm{MgH}_{2}$ to surfactants. At the initial stage of the reaction, the lower the surface tension, the more hydrogen generation. And at the middle and late stages, the foam layer caused by the low surface tension impedes the hydrogen generation. However, there are some differences when TPABr added to the solution. As shown in Table 4, the surface tension decreases from $71.57 \mathrm{mN} / \mathrm{m}$ to $61.54 \mathrm{mN} / \mathrm{m}$ and then increases to $69.23 \mathrm{mN} / \mathrm{m}$ with increase of the ratio of $\mathrm{MgH}_{2}$ to $\mathrm{TPABr}$. And the hydrogen generation has the same trend, the final hydrogen yield are ranked as follows: $\mathrm{MgH}_{2}$ : $\mathrm{TPABr}=5: 1>\mathrm{MgH}_{2}: \mathrm{TPABr}=1: 1>\mathrm{MgH}_{2}: \mathrm{TPABr}$ $=10: 1>\mathrm{MgH}_{2}: \mathrm{TPABr}=100: 1>\mathrm{MgH}_{2}$.

Figure 6(d) illustrates that $\mathrm{Mg}(\mathrm{OH})_{2}$ grows evenly around the surface of $\mathrm{MgH}_{2}$, like a blooming flower. The "petals"- $\mathrm{Mg}(\mathrm{OH})_{2}$ form uniform channels instead of coating $\mathrm{MgH}_{2}$ in the form of flakes. Because of the better passability, $\mathrm{H}_{2} \mathrm{O}$ molecules can contact $\mathrm{MgH}_{2}$ through these channels. Contrarily, the high concentration of $\mathrm{TPABr}$ may cause $\mathrm{Mg}(\mathrm{OH})_{2}$ to grow as many points as possible on the surface of $\mathrm{MgH}_{2}$ forming narrow and long channels. As a result, it is difficult for $\mathrm{H}_{2} \mathrm{O}$ molecules to reach the surface of $\mathrm{MgH}_{2}$ through the channels.

When the surface tension decreases to $61.54 \mathrm{mN} / \mathrm{m}$, there is no obvious foam layer. Thus, $\mathrm{H}_{2}$ can easily escape from the solution. In addition, TPABr inhibits the formation of passivation layer and prolongs the time for $\mathrm{Mg}(\mathrm{OH})_{2}$ to reach the critical volume. It may also because of the adsorptive effect of TPABr. When TPABr absorbs on the surface of $\mathrm{Mg}(\mathrm{OH})_{2}$ newly formed and the adsorption layer cannot only inhibit the growth of the $\mathrm{Mg}(\mathrm{OH})_{2}[31,32]$, it also reduces the surface energy. Therefore, the interaction among the particles is weakened, and it prevents the agglomeration among the particles [33-35].

3.3. Effect of Nonionic Surfactant. Nonionic surfactants are different in structure from other ionic surfactants. The main hydrophilic group is an ether group that does not dissociate in aqueous solution. It has an excellent wetting effect and superior antideposition ability for particles.

As shown in Figure 7, when the time is $100 \mathrm{~s}$, the hydrogen generation of $\mathrm{MgH}_{2}$ : Ecosol $507=100: 1$ is $50 \%$ higher 


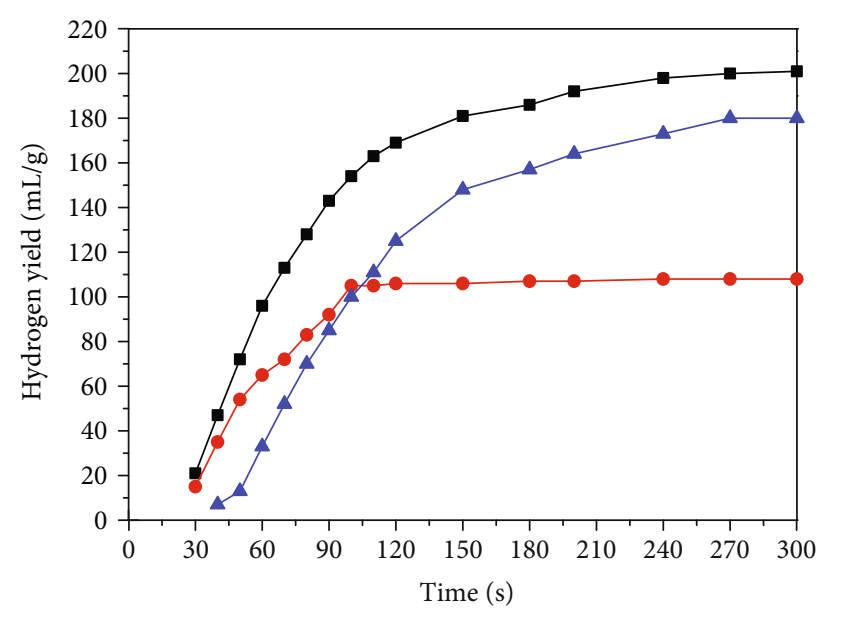

$$
\begin{aligned}
& \rightarrow-\mathrm{MgH}_{2}: \mathrm{E} \operatorname{cosol} 507=100: 1 \\
& \longrightarrow \mathrm{MgH}_{2}: \mathrm{E} \operatorname{cosol} 507=10: 1 \\
& \simeq \mathrm{MgH}_{2}
\end{aligned}
$$

Figure 7: The effect of different Ecosol 507 dosages on hydrogen generation.

TABLE 5: Surface tension values of aqueous solutions with different Ecosol 507 dosages.

\begin{tabular}{lc}
\hline Ratio & ST $(\mathrm{mN} / \mathrm{m})$ \\
\hline Water & 71.57 \\
$\mathrm{MgH}_{2}:$ Ecosol $507=100: 1$ & 28.38 \\
$\mathrm{MgH}_{2}:$ Ecosol $507=10: 1$ & 20.49 \\
\hline
\end{tabular}

than that without surfactants. When the time is $300 \mathrm{~s}$, the hydrogen generation of $\mathrm{MgH}_{2}$ : Ecosol $507=10: 1$ is $40 \%$ lower than that without surfactants, but the hydrogen generation of $\mathrm{MgH}_{2}$ : Ecosol 507 = 100: 1 is $11.7 \%$ higher than it.

It can be seen from Table 5 that Ecosol 507 significantly reduces the surface tension. In this experiment, we observed the volume of the foam was far much larger than the other surfactants. When the reaction time is over $100 \mathrm{~s}$, the foam of $\mathrm{MgH}_{2}$ : Ecosol $507=10: 1$ fills the whole three-necked flask and seriously weakens diffusion of $\mathrm{H}_{2}$.

3.4. Comparison of Maximum Hydrogen Generation. Sort by maximum hydrogen generation (Figure 8): TPABr $>$ SDBS $>$ Ecosol $507>$ OTAC $>$ no surfactants $>$ AES $\approx$ FMES -70 .

3.5. Analysis of SEM. In order to further explore the influence of surfactants on the hydrogen generation and the hydrogen generation rate, samples are observed and analyzed by SEM.

Figure 6 shows the scanning electron microscope pictures of the products of four illustrative experiments. The surface of $\mathrm{MgH}_{2}$ particles used in the experiments can be observed in Figure 6(a) with a smooth surface and localized layered deposition. Figure 6(b) shows the morphology of $\mathrm{MgH}_{2}$ after the hydrolysis reaction without surfactants. The smooth surface is pitted by $\mathrm{H}_{2} \mathrm{O}$ molecules. There are two forms of $\mathrm{Mg}(\mathrm{OH})_{2}$ on the surface of $\mathrm{MgH}_{2}$. One forms a dense passiv-

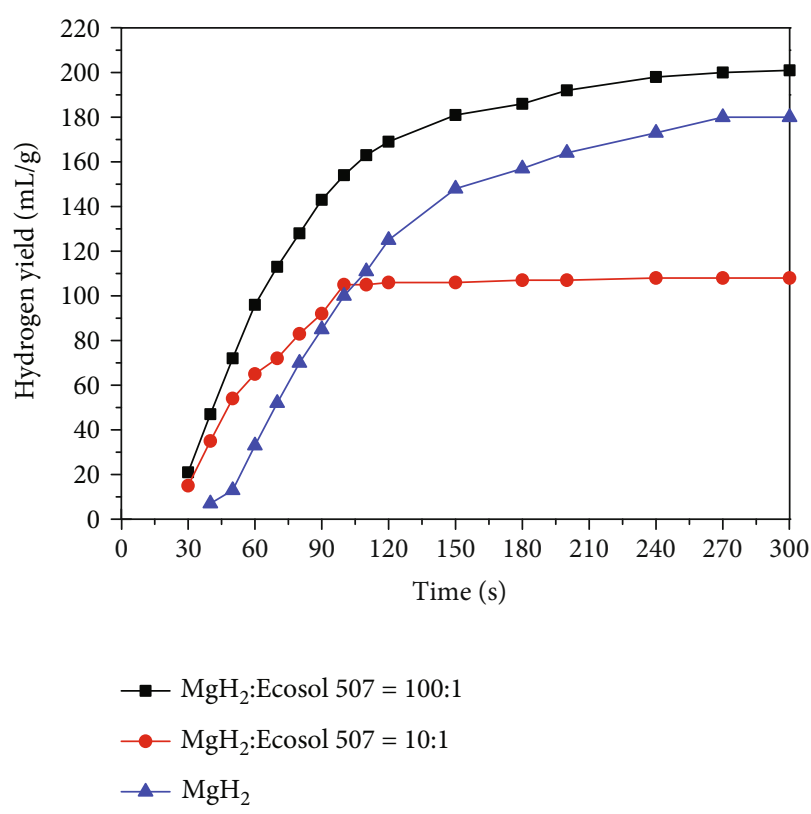

FIgURE 8: Comparison of hydrogen generation curves of $\mathrm{MgH}_{2}$.

ation layer that prevents $\mathrm{H}_{2} \mathrm{O}$ molecules from contacting with $\mathrm{MgH}_{2}$, and the other forms a discontinuous layered structure in the form of three-dimensional stacking that provides channels for $\mathrm{H}_{2} \mathrm{O}$ molecules.

Surfactants can improve the morphology of the hydrolysate through interface control. After adding SDBS $\left(\mathrm{MgH}_{2}: \mathrm{SDBS}=300: 1\right)$, it is observed that the area of the coating layer in Figure 6(c) is significantly smaller than that in Figure 6(b), the relative stratigraphic structure becomes more and more evenly distributed on the hydrogenated, and the number and diameter of the channels have also increased. Therefore, the addition of SDBS increases the hydrogen generation and the hydrogen generation rate of the reaction system compared without surfactants. On one hand, adding TPABr increases the growth sites of $\mathrm{Mg}(\mathrm{OH})_{2}$ to make the distribution of $\mathrm{Mg}(\mathrm{OH})_{2}$ more uniform; on the other hand, it makes the directional growth of $\mathrm{Mg}(\mathrm{OH})_{2}$, which further changes the morphology. Compared with Figure 6(b), the hydrolyzed product in Figure 6(d), there is no cladding layer; instead, a layered structure is formed by three-dimensional accumulation. Compared with Figure 6(c), the layered structure in Figure 6(d) is more uniform and stable (i.e., the distribution and the diameter of channels is more uniform and larger), and it allows more $\mathrm{H}_{2} \mathrm{O}$ molecules to reach the surface of $\mathrm{MgH}_{2}$ improving the hydrogen generation rate. At the same time, $\mathrm{Mg}(\mathrm{OH})_{2}$ crystals formed by the reaction grow in the form of threedimensional accumulation instead of encapsulating $\mathrm{MgH}_{2}$, so that $\mathrm{H}_{2} \mathrm{O}$ can react with $\mathrm{MgH}_{2}$ constantly.

\section{Conclusion}

(1) The addition of surfactants reduces the surface tension of the liquid, improves the wetting effect of the liquid on the $\mathrm{MgH}_{2}$, and increases the hydrogen 
generation and the hydrogen generation rate at the initial stage of the hydrolysis

(2) With the addition of surfactants, the reaction system is more prone to foam. When these foams gather to form a foam layer, it hinders the escape of hydrogen and reduces the hydrogen generation and the hydrogen generation rate

(3) Surfactants can change the morphology of $\mathrm{Mg}(\mathrm{OH})_{2}$. $\mathrm{Mg}(\mathrm{OH})_{2}$ stake in three-dimensions to form a discontinuous layered structure improving the continuity of the hydrolysis reaction

(4) When the surfactant concentration reaches CMC, the self-polymerization of surfactants inhibits the separation of $\mathrm{Mg}(\mathrm{OH})_{2}$ and affects the dispersion effect

(5) On one hand, the negatively charged groups of surfactants may combine with $\mathrm{H}^{+}$in the water, which reduces the concentration of $\mathrm{H}^{+}$affecting the hydrogen generation; on the other hand, the positively charged groups may combine with $\mathrm{OH}^{-}$inhibiting the nucleated growth of $\mathrm{Mg}(\mathrm{OH})_{2}$

\section{Data Availability}

The experimental data used to support the findings of this study are included within the article.

\section{Conflicts of Interest}

The authors declare no conflict of interest.

\section{Acknowledgments}

This work is financially supported by National Natural Science Foundation of China (No.51976112).

\section{References}

[1] D. J. C. Mackay and D. Hafemeister, "Sustainable energywithout the hot air," American Journal of Physics, vol. 78, no. 2, pp. 222-223, 2010.

[2] R. B. Gupta, Hydrogen Fuel: Production, Transport, and Storage, CRC Press, 2009.

[3] J. E. Mason, "World energy analysis: H2 now or later?," Energy Policy, vol. 35, no. 2, pp. 1315-1329, 2007.

[4] A. C. D. Chaklader, "Hydrogen generation from water split reaction," US Patent 6440385, 2002.

[5] S. I. Orimo, Y. Nakamori, J. R. Eliseo, A. Züttel, and C. M. Jensen, "Complex hydrides for hydrogen storage," Chemical Reviews, vol. 107, no. 10, pp. 4111-4132, 2007.

[6] W. Grochala and P. P. Edwards, "Thermal decomposition of the non-interstitial hydrides for the storage and production of hydrogen," Chemical Reviews, vol. 104, no. 3, pp. 12831316, 2004.

[7] H. Kato and A. Kudo, "New tantalate photocatalysts for water decomposition into H2 and O2," Chemical Physics Letters, vol. 295, no. 5-6, pp. 487-492, 1998.
[8] M. A. Rosen, "Advances in hydrogen production by thermochemical water decomposition: a review," Energy, vol. 35, no. 2, pp. 1068-1076, 2010.

[9] A. C. Dillon and M. J. Heben, "Hydrogen storage using carbon adsorbents: past, present and future," Applied Physics A Materials Science \& Processing, vol. 72, no. 2, pp. 133-142, 2001.

[10] S. Satyapal, J. Petrovic, C. Read, G. Thomas, and G. Ordaz, "The U.S. Department of Energy's National Hydrogen Storage Project: progress towards meeting hydrogen-powered vehicle requirements," Catalysis Today, vol. 120, no. 3-4, pp. 246256, 2007.

[11] Y. Wang, Z. Ding, X. Li et al., "Improved hydrogen storage properties of $\mathrm{MgH} 2$ by nickel@nitrogen-doped carbon spheres," Dalton Transactions, vol. 49, no. 11, pp. 3495-3502, 2020.

[12] M. Ismail, M. S. Yahya, N. A. Sazelee, N. A. Ali, and N. S. Mustafa, "The effect of $\mathrm{K}_{2} \mathrm{SiF}_{6}$ on the $\mathrm{MgH}_{2}$ hydrogen storage properties," Journal of Magnesium and Alloys, vol. 8, no. 3, pp. 832-840, 2020.

[13] T. Biasetti Andrés, L. Mendoza Zélis, and M. Marcos, "Differences in the heterogeneous nature of hydriding/dehydriding kinetics of $\mathrm{MgH}_{2}-\mathrm{TiH}_{2}$ nanocomposites," International Journal of Hydrogen Energy, vol. 45, no. 51, pp. 27421-27433, 2020.

[14] N. A. Ali, N. H. Idris, M. F. M. Din, M. S. Yahya, and M. Ismail, "Nanoflakes $\mathrm{MgNiO}_{2}$ synthesised via a simple hydrothermal method and its catalytic roles on the hydrogen sorption performance of $\mathrm{MgH}_{2}$," Journal of Alloys and Compounds, vol. 796, pp. 279-286, 2019.

[15] J. Zhang, L. He, Y. Yao et al., "Catalytic effect and mechanism of $\mathrm{NiCu}$ solid solutions on hydrogen storage properties of MgH2," Renewable Energy, vol. 154, pp. 1229-1239, 2020.

[16] F. A. Halim Yap, N. N. Sulaiman, and M. Ismail, "Understanding the dehydrogenation properties of $\mathrm{MgH} 2$ catalysed by Na3AlF6," International Journal of Hydrogen Energy, vol. 44, no. 58, pp. 30583-30590, 2019.

[17] N. A. Sazeleea, N. H. Idrisa, M. F. M. Din, M. S. Yahya, N. A. Ali, and M. Ismail, " $\mathrm{LaFeO}_{3}$ synthesised by solid-state method for enhanced sorption properties of $\mathrm{MgH} 2$," Results in Physics, vol. 16, pp. 102844-102850, 2020.

[18] N. H. Idris, N. S. Mustafa, and M. Ismail, "MnFe2O4 nanopowder synthesised via a simple hydrothermal method for promoting hydrogen sorption from $\mathrm{MgH} 2$," International Journal of Hydrogen Energy, vol. 42, no. 33, pp. 2111421120, 2017.

[19] N. A. Ali, N. H. Idris, M. F. M. Din et al., "Nanolayer-likeshaped $\mathrm{MgFe}_{2} \mathrm{O}_{4}$ synthesised via a simple hydrothermal method and its catalytic effect on the hydrogen storage properties of $\mathrm{MgH}_{2}$," RSC Advances, vol. 8, no. 28, pp. 15667-15674, 2018.

[20] V. C. Y. Kong, F. R. Foulkes, D. W. Kirk, and J. T. Hinatsu, "Development of hydrogen storage for fuel cellgenerators. i: Hydrogen generation using hydrolysishydrides," International Journal of Hydrogen Energy, vol. 24, no. 7, pp. 665-675, 1999.

[21] C. Wu, Y. Bai, and F. Wu, "Fast hydrogen generation from $\mathrm{NaBH} 4$ solution accelerated by ferric catalysts," Materials Letters, vol. 62, no. 27, pp. 4242-4244, 2008.

[22] C. Cento, P. Gislon, and P. P. Prosini, "Hydrogen generation by hydrolysis of $\mathrm{NaBH} 4$," International Journal of Hydrogen Energy, vol. 34, no. 10, pp. 4551-4554, 2009.

[23] M. S. Zou, R. J. Yang, X. Y. Guo, H. T. Huang, J. Y. He, and P. Zhang, "The preparation of Mg-based hydro-reactive 
materials and their reactive properties in seawater," International Journal of Hydrogen Energy, vol. 36, no. 11, pp. 64786483, 2011.

[24] K. Azzaoui, E. Mejdoubi, S. Jodeh et al., "Eco friendly green inhibitor Gum Arabic (GA) for the corrosion control of mild steel in hydrochloric acid medium," Corrosion Science, vol. 129, pp. 70-81, 2017.

[25] T. Arslan, F. Kandemirli, E. E. Ebenso, I. Love, and H. Alemu, "Quantum chemical studies on the corrosion inhibition of some sulphonamides on mild steel in acidic medium," Corrosion Science, vol. 51, no. 1, pp. 35-47, 2009.

[26] M. Drach, A. Andrzejewska, J. Narkiewicz-Michałek, W. Rudziński, and L. K. Koopal, "Theoretical modeling of cationic surfactants aggregation at the silica/aqueous solution interface: effects of $\mathrm{pH}$ and ionic strength," Physical Chemistry Chemical Physics, vol. 4, no. 23, pp. 5846-5855, 2002.

[27] I. A. Khan, A. J. Khanam, M. S. Sheikh, and Kabir-ud-Din, "Influence of ionic and nonionic hydrotropes on micellar behavior of a cationic gemini surfactant butanediyl-1,4-bis(dimethylcetylammonium bromide)," Journal of Colloid and Interface Science, vol. 359, no. 2, pp. 467-473, 2011.

[28] M. Qiao, J. Chen, C. Yu, S. Wu, N. Gao, and Q. Ran, "Gemini surfactants as novel air entraining agents for concrete," Cement and Concrete Research, vol. 100, pp. 40-46, 2017.

[29] A. Bureiko, A. Trybala, N. Kovalchuk, and V. Starov, "Current applications of foams formed from mixed surfactant-polymer solutions," Advances in Colloid and Interface Science, vol. 222, pp. 670-677, 2015.

[30] J. Zheng, D. C. Yang, W. Li, H. Fu, and X. Li, "Promoting H2 generation from the reaction of $\mathrm{Mg}$ nanoparticles and water using cations," Chemical Communications, vol. 49, no. 82, pp. 9437-9439, 2013.

[31] H. Dhaouadi, H. Chaabane, and F. Touati, " $\mathrm{Mg}(\mathrm{OH}) 2$ nanorods synthesized by a facile hydrothermal method in the presence of CTAB," Nano-Micro Letters, vol. 3, no. 3, pp. 153-159, 2011.

[32] Z. Hu, Y. Ji, S. Hou, and X. Wu, "Minimizing the effect of neardistance dielectric sensitivity on retrieving average aspect ratio of gold nanorod by optical extinction spectroscopy: in the case of CTAB adsorption," Chinese Science Bulletin, vol. 59, no. 16, pp. 1822-1831, 2014.

[33] J. P. Zheng and T. R. Jow, "A new charge storage mechanism for electrochemical capacitors and charge storage density vs. crystalline structure of metal oxides," MRS Proceedings, vol. 393, no. 1, pp. 439-444, 1995.

[34] M. G. Sullivan, R. Kötz, and O. Haas, “Thick active layers of electrochemically modified glassy carbon. Electrochemical impedance studies," Journal of the Electrochemical Society, vol. 147, no. 1, pp. 308-317, 2000.

[35] H. Y. Lee and J. B. Goodenough, "Supercapacitor behavior with $\mathrm{KCl}$ electrolyte," Journal of Solid State Chemistry, vol. 144, no. 1, pp. 220-223, 1999. 